\title{
8
}
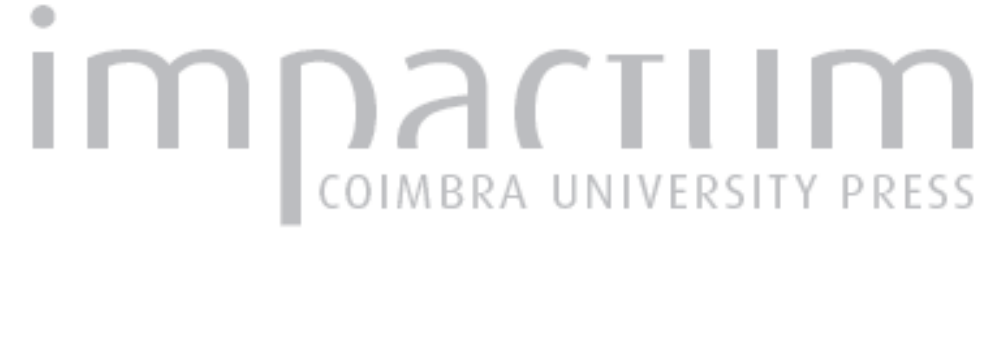

\section{FIMT - fire incident mapping tool: aplicação SIG em incêndios florestais - estudo de caso em Portugal}

Autor(es): $\quad$ Rocha, Hugo; Monteiro, José Massano

Publicado por: Associação Portuguesa de Riscos, Prevenção e Segurança

URL persistente:

URl:http://hdl.handle.net/10316.2/35847

DOI:

DOI:http://dx.doi.org/10.14195/1647-7723_20

Accessed : $\quad$ 26-Apr-2023 15:59:19

A navegação consulta e descarregamento dos títulos inseridos nas Bibliotecas Digitais UC Digitalis, UC Pombalina e UC Impactum, pressupõem a aceitação plena e sem reservas dos Termos e Condições de Uso destas Bibliotecas Digitais, disponíveis em https://digitalis.uc.pt/pt-pt/termos.

Conforme exposto nos referidos Termos e Condições de Uso, o descarregamento de títulos de acesso restrito requer uma licença válida de autorização devendo o utilizador aceder ao(s) documento(s) a partir de um endereço de IP da instituição detentora da supramencionada licença.

Ao utilizador é apenas permitido o descarregamento para uso pessoal, pelo que o emprego do(s) título(s) descarregado(s) para outro fim, designadamente comercial, carece de autorização do respetivo autor ou editor da obra.

Na medida em que todas as obras da UC Digitalis se encontram protegidas pelo Código do Direito de Autor e Direitos Conexos e demais legislação aplicável, toda a cópia, parcial ou total, deste documento, nos casos em que é legalmente admitida, deverá conter ou fazer-se acompanhar por este aviso.

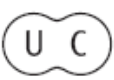




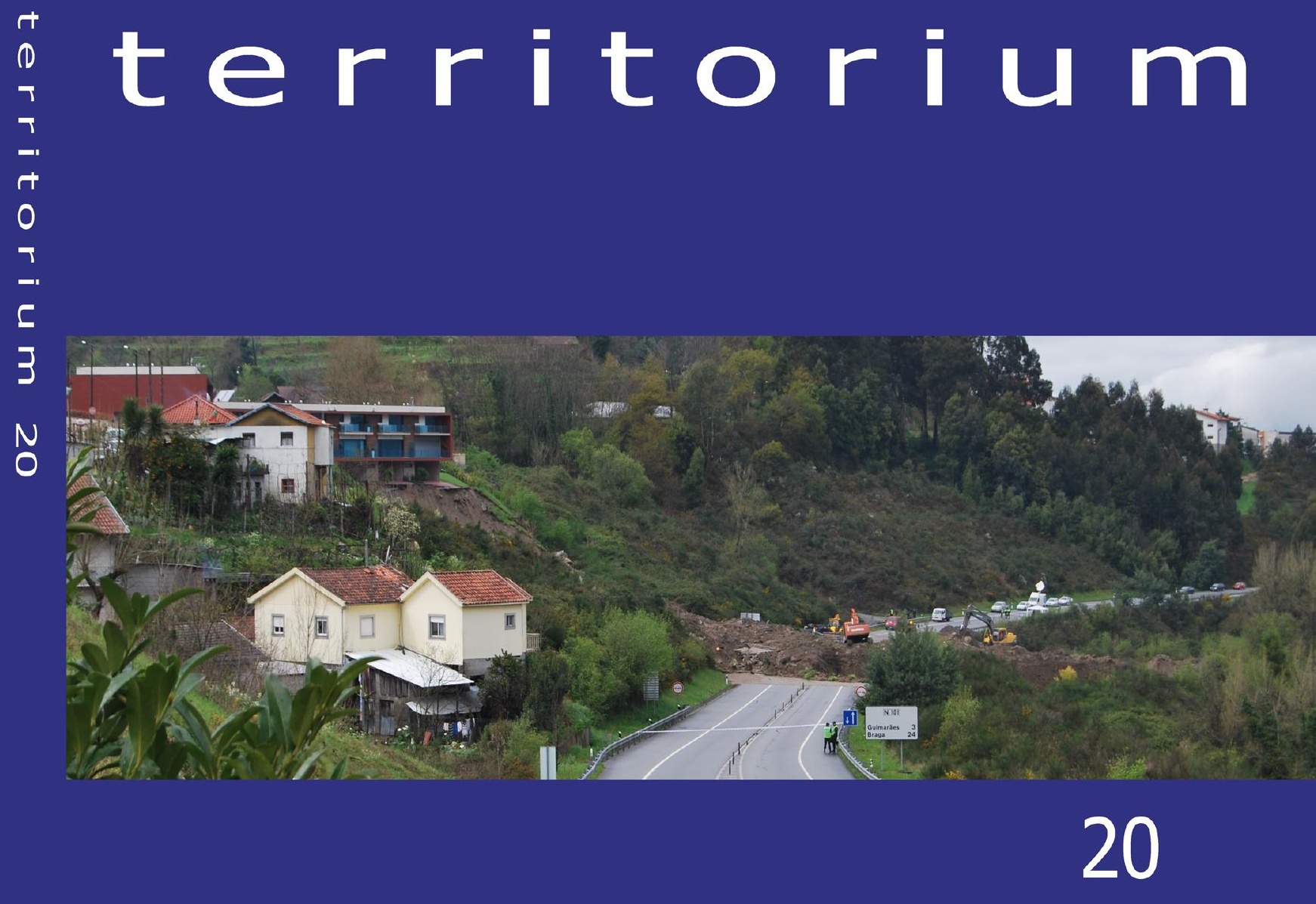

Riscos, População e Segurança 


\section{NOTAS, NOTÍCIAS E RECENSÕES}

FIMT - FIRE INCIDENT MAPPING TOOL APLICAÇÃO SIG EM INCÊNDIOS FLORESTAIS - ESTUDO DE CASO EM PORTUGAL*

Hugo Rocha

Bombeiros Voluntários de Famalicão da Serra hhnrocha@gmail.com

José Massano Monteiro

IPCB - Escola Superior Agrária jamonteiro@ipcb.pt

\section{Introdução}

A missão dos bombeiros e dos seus órgãos de coordenação, no nosso caso, no conceito da Autoridade Nacional de Protecção Civil é planear, coordenar e executar a política de Protecção Civil, designadamente: a prevenção e reacção a acidentes graves e catástrofes, a protecção e socorro das populações e a superintendência da actividade dos bombeiros.

Com o crescente desenvolvimento e complexidade dos incidentes, os bombeiros e demais entidades responsáveis pelo socorro devem estar aptos a dar uma resposta eficiente no dia-a-dia e, também, devem poder ter à sua disposição as melhores ferramentas disponíveis, tanto a nível de técnicas como em métodos de preparação, para assim poderem corresponder às expectativas da população que com eles conta nas demais situações de emergência.

Uma dessas situações de emergência, que, no caso do nosso país, requer maior empenhamento dos organismos de protecção civil, são os incêndios florestais.

Assim, a preparação para o combate a esta catástrofe passa pela prevenção, combate e medidas pós-acidente.

Durante os incêndios florestais, os Sistemas de Informação Geográfica (doravante designados pela sigla SIG) poderão tornar-se um instrumento de muita utilidade, pois fornecem às entidades responsáveis a capacidade de determinar, delinear e adequar tácticas e estratégias, de maneira a escolher a melhor forma de supressão do incêndio.

Uma vez que a ferramenta que vamos utilizar neste trabalho é vocacionada para o combate a incêndios florestais, todo o trabalho se irá desenvolver em redor da mesma.

O Fire Incident Mapping Tool (doravante designado FIMT) é uma extensão para o software ArcGis, versão
9.2, 9.3 e 10, e é uma ferramenta de suporte à decisão para incêndios florestais, sendo utilizada hoje em dia por todo o território dos Estados Unidos da América e estando a sua gestão ao encargo dos respectivos serviços florestais.

\section{Material e Métodos}

Material

O trabalho desenvolveu-se com recurso ao ambiente SIG e foi utilizado para a sua realização o Software Arclnfo 9.3 (ESRI), com a extensão Fire Incident Mapping Tool (FIMT), versão 9.3.0.9.

Foi também utilizada a Simbologia utilizada para realização da Situação Táctica (doravante designada SITAC) no combate aos incêndios florestais em Portugal.

Foram ainda utilizadas as seguintes bases cartográficas:

- Folhas do Distrito da Guarda da Carta Militar de Portugal à escala 1:25000 (edições de 1997 e 1998), em formato raster $n .^{\circ} 225,226,236$ e 237 (Fonte: IGeoE);

- Altimetria, curvas de nível em formato vectorial, com uma equidistância de $10 \mathrm{~m}$, correspondentes às folhas n. ${ }^{\circ} 225,226,236$ e 237 da Carta Militar de Portugal à escala 1:25000 (Fonte: IGeoE);

- Ortofotomapas (correspondentes às folhas n. ${ }^{\circ} 225$, 226, 236 e 237 da Carta Militar de Portugal à escala $1: 25000$ ), escala 1:10000, resolução espacial 0,5 m, cobertura fotográfica de 2005 (Fonte: IGP);

- Cartografia temática das áreas ardidas do Distrito da Guarda (Fonte: ICNF);

- Limites administrativos, concelhos e freguesias (Fonte: CAOP, 2009).

* O texto desta nota corresponde à comunicação apresentada ao VII Encontro Nacional de Riscos e I Forum ISCIA, tendo sido submetida para revisão em 05-11-2012, e aceite para publicação em 12-11-2012.

Esta nota é parte integrante da Revista Territorium, n. ${ }^{\circ} 20,2013,{ }^{\circ}$ RIscos, ISBN: 0872- 8941. 
Fire Incident Mapping Tool (FIMT)

A extensão Fire Incident Mapping Tool (FIMT) para ArcGIS, ArcMap versão 9.x, foi inicialmente desenvolvida para o software 8.3.

Este software foi desenvolvido nos Estados Unidos da América, pelos seus serviços florestais, com a intenção de ser de fácil instalação e utilização em Windows 2000, Windows NT e Windows XP. Existe, no entanto, uma versão lançada para ArcGIS 10, sendo que é apenas uma versão de teste e sujeita a alterações.

O objectivo principal deste software é ser uma ferramenta de apoio para auxílio na criação e gestão de dados geográficos de um incêndio florestal, sendo também totalmente compatível com o Incident Command System (ICS), o GIS Standard Operating Procedures (GSTOP) e o GIS Specialist (GISS).

A ideia surgiu no início de 2001 e o projecto começou a ser desenvolvido em Agosto de 2001, tendo sido aprovado pelos serviços e apresentado como uma aplicação para coordenação de incêndios florestais durante o ano de 2005.

Esta aplicação foi desenvolvida em Denver, no Colorado, EUA, sendo que hoje em dia a sua manutenção executase no National Wildland Fire Coordinating Group (NWGC) em Boise, Idaho, Estados Unidos da América.

Neste momento, o FIMT é a única aplicação que cumpre as normas NWCG SIG Standard Operating Procedure.

Apesar do seu desenvolvimento ter sido para aplicação no combate aos incêndios florestais, está a padronizar-se de forma a ser utilizada em mais situações de emergência.

Como a aplicação é auto-suficiente e a base de dados geográfica produzida é partilhável, permite que possa ser utilizada por qualquer pessoa que use a plataforma SIG da ESRI, o ArcGIS.

A primeira vez que o software foi utilizado, em versão teste, foi no Verão de 2003. Em 2004, o FIMT começou a ser conhecido em todos os Estados Unidos e Canadá, começando aí a sua verdadeira aplicação no combate aos incêndios florestais (em 2005).

Actualmente, o FIMT é usado por todas as agências responsáveis pela coordenação e pelo combate aos incêndios florestais nos EUA.

\section{Metodologia}

Foi utilizado o software Fire Incident Mapping Tool (FIMT) de forma a exemplificar o seu funcionamento e tratamento de dados. Esta exemplificação surgiu com o intuito de perceber se o software seria ou não aconselhável para utilização em Portugal.
O trabalho realizado constituiu a demonstração e aplicação do FIMT num caso de estudo idealizado para o presente trabalho para este trabalho. Tratar-se-á do combate a um incêndio florestal que terá início no distrito da Guarda, concelho do Sabugal, na freguesia de Casteleiro.

\section{Resultados}

A barra de ferramentas do FIMT - Agrupamento de todas as ferramentas disponíveis

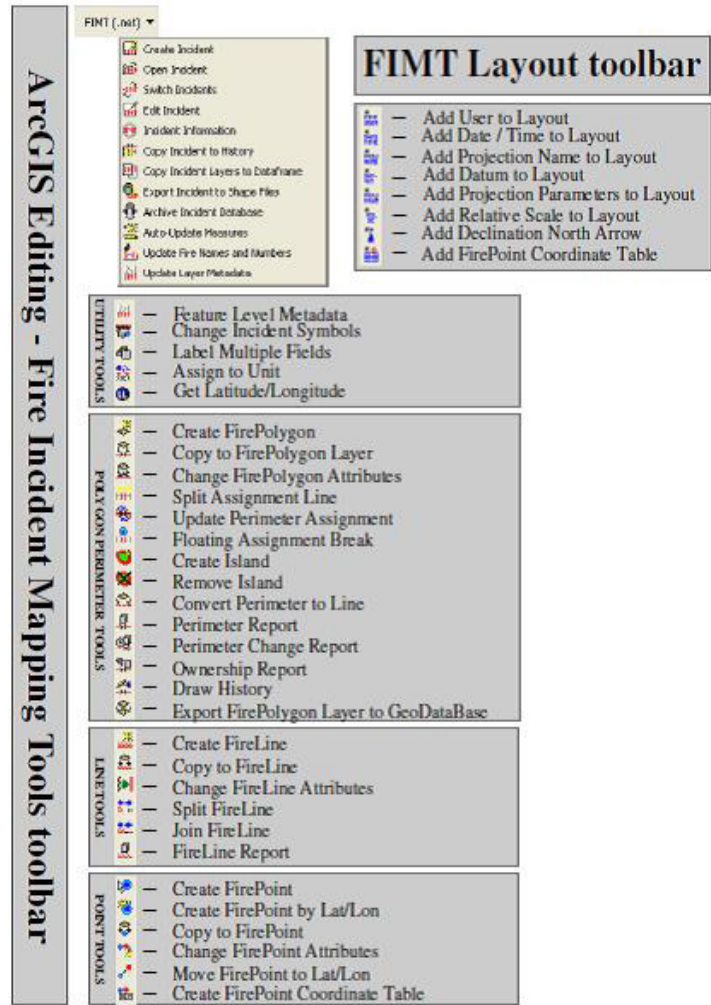

Fig. 1 - Barra de Ferramentas FIMT - Aparece neste programa como o agrupamento de todas as ferramentas disponíveis.

\section{Criação de um novo incidente}

Para efectuar a criação da geodatabase do incidente, é necessário clicar no ícone de FIMT, do lado esquerdo do ecrã e clicar "new incident", tendo de seguida proceder ao preenchimento de dados necessários ao incidente.

Incident Personal Geodatabase: cada novo incidente é gravado numa nova geodatabase armazenada no local selecionado pelo usuário. É obrigatória a criação de uma nova geodatabase por cada incidente.

\section{Criação de um novo FirePoint}

Para criar o ínicio de um incendio, esta ferramenta permite recorrer a duas formas, através do local inicial ou de uma forma mais precisa, através das coordenadas do ponto inicial. 


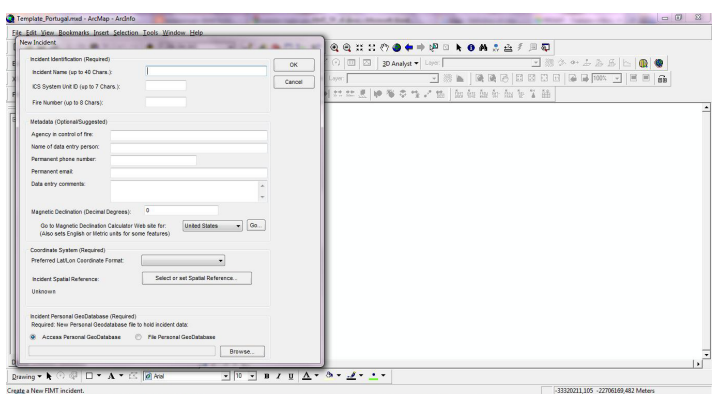

Fig. 2 - Preenchimento de dados necessários no incidente.

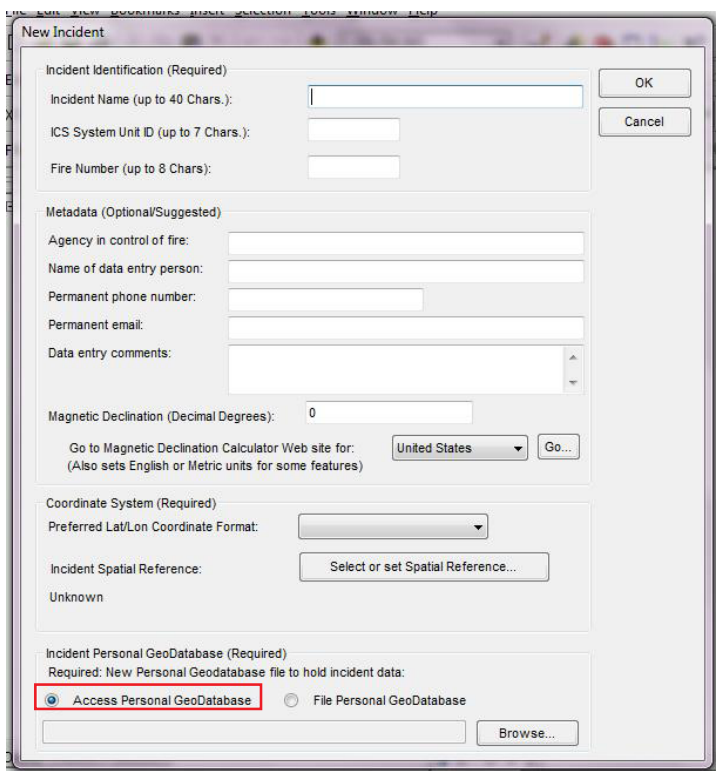

Fig. 3 - Tabela de preenchimento de um novo incidente.

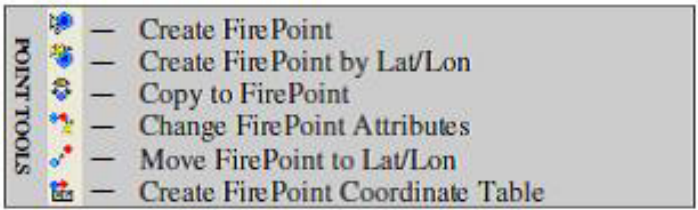

Fig. 4 - Ferramentas para edição de Pontos (Point Tools).

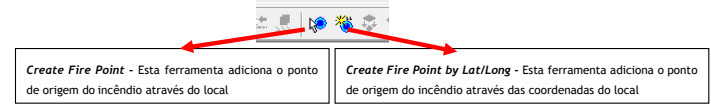

Fig. 5 - Formas de inserção de um tema de pontos.

\section{Criação de um novo Fireline}

Várias opções para a criação de linhas, como: extensão de frentes de fogo, o seu número, caminhos, caminhos de fuga, existência de aceiros, local de utilização de fogo táctico.

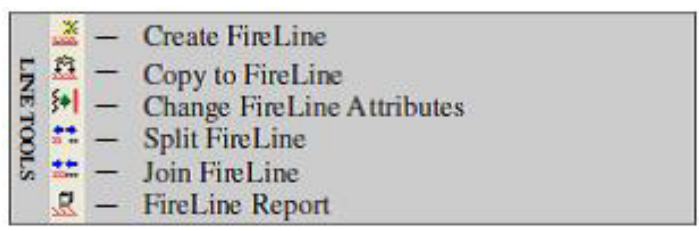

Fig. 6 - Ferramentas para edição de Linhas (Line Tools).

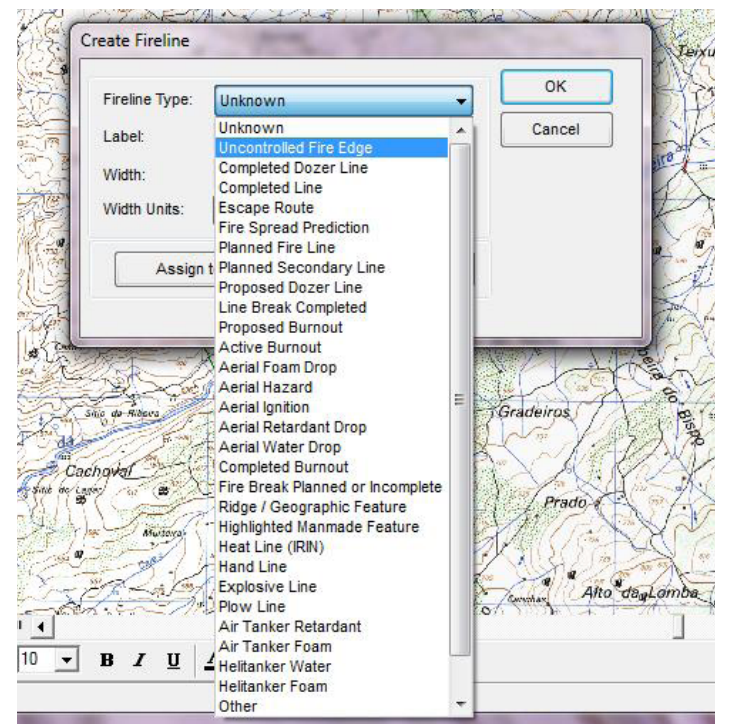

Fig. 7 - Opções enquadradas no Tema FireLine.

\section{Criação de um novo FirePolygon}

Permite a criação de polígonos, para gerar um perímetro maior, "ilhas" (área não queimada) que dentro do perimtro do incendio podem alocar habitações, pessoas e bens.

Sempre que um FirePolygon é criado, é também criada uma característica correspondente no PerimeterSector. As linhas PerimeterSector são armazenadas no Incident PerimeterSector. Esta característica é importante porque permite organizar o perímetro de fogo em vários sectores operacionais.

\begin{tabular}{|c|c|}
\hline 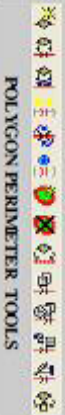 & $\begin{array}{l}\text { - Create FirePolygon } \\
\text { - Copy to FirePolygon Layer } \\
\text { - Change FirePolygon Attributes } \\
\text { - Split Assignment Line } \\
\text { - Update Perimeter Assignment } \\
\text { - Floating Assignment Break } \\
\text { - Create Island } \\
\text { - Remove Island } \\
\text { - Convert Perimeter to Line } \\
\text { - Perimeter Report } \\
\text { - Perimeter Change Report } \\
\text { - Ownership Report } \\
\text { - Draw History }\end{array}$ \\
\hline
\end{tabular}

Fig. 8 - Ferramentas para edição de Polígonos (Polygon Perimeter Tools),

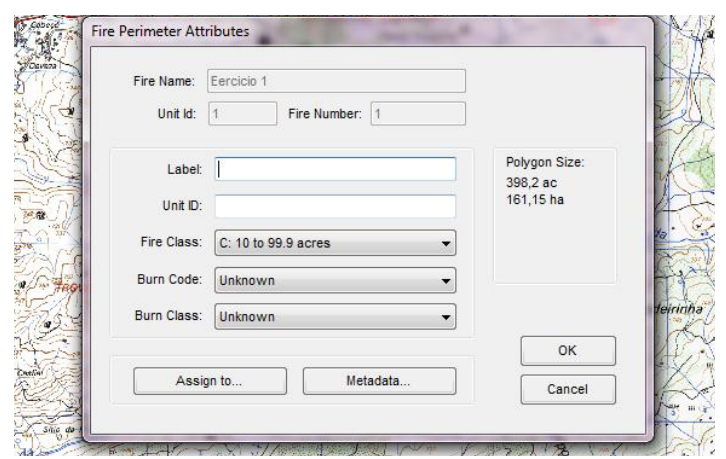

Fig. 9 - Opções enquadradas no Tema FirePerimeter. 


\section{Projecto FIMT}

Simulação de um incêndio florestal no Distrito da Guarda, Concelho do Sabugal, Freguesia do Casteleiro.

Depois de criado o Incidente e do preenchimento dos seus dados guarda-se a geodatabase na pasta correspondente.

A partir desse momento carrega-se no programa a informação gráfica necessária para aquela ocorrência e começa-se a desenrolar a situação táctica.

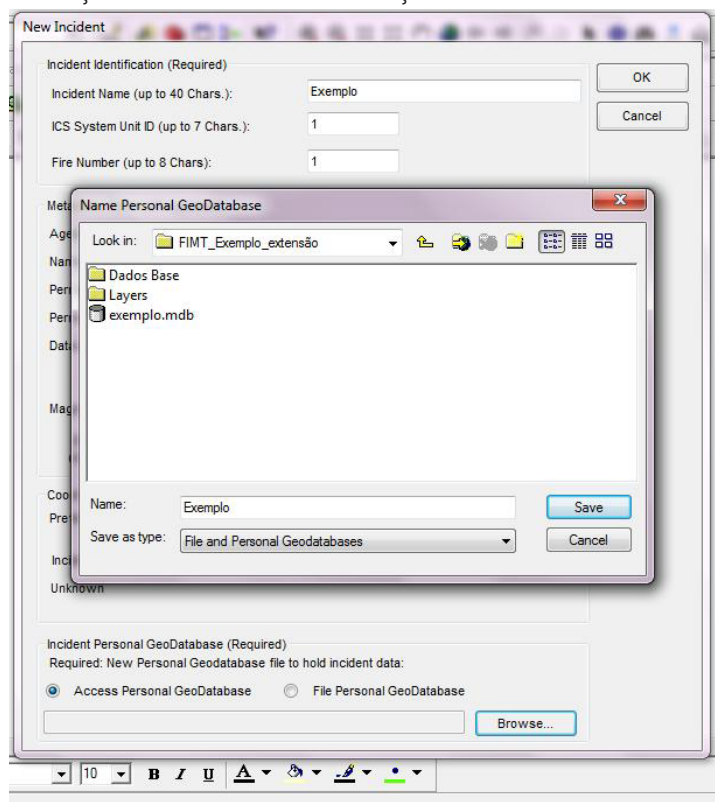

Fig. 10 - Criação da Personal Geodatabase.

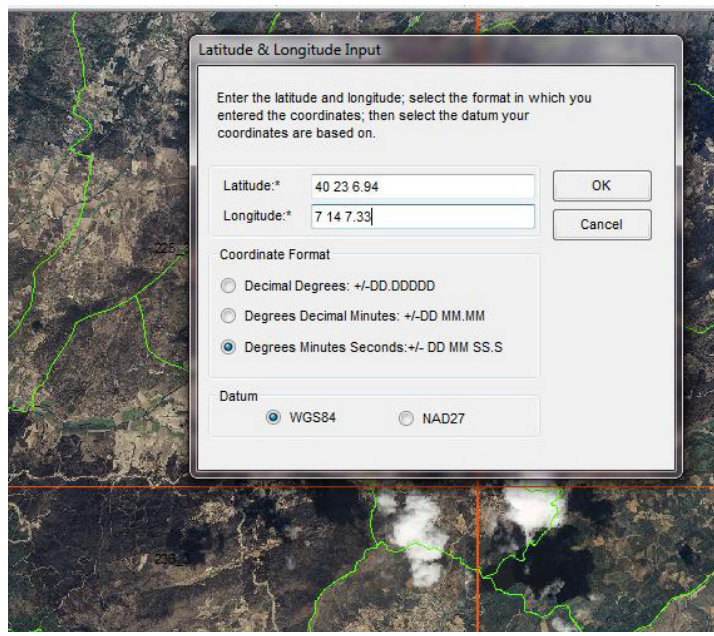

Fig. 12 - Colocação das coordenadas do ponto de ignição inicial.

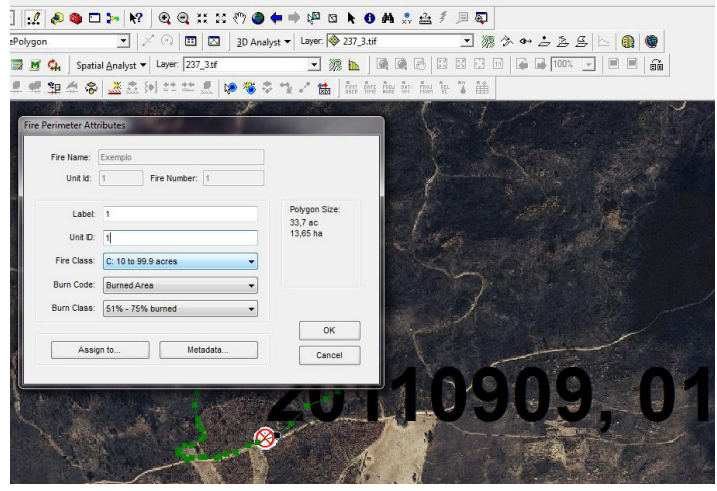

Fig. 13 - Atributos de um FirePolygon.

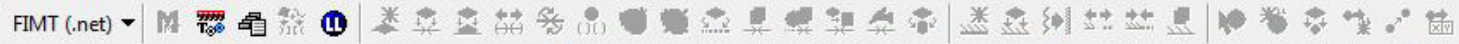

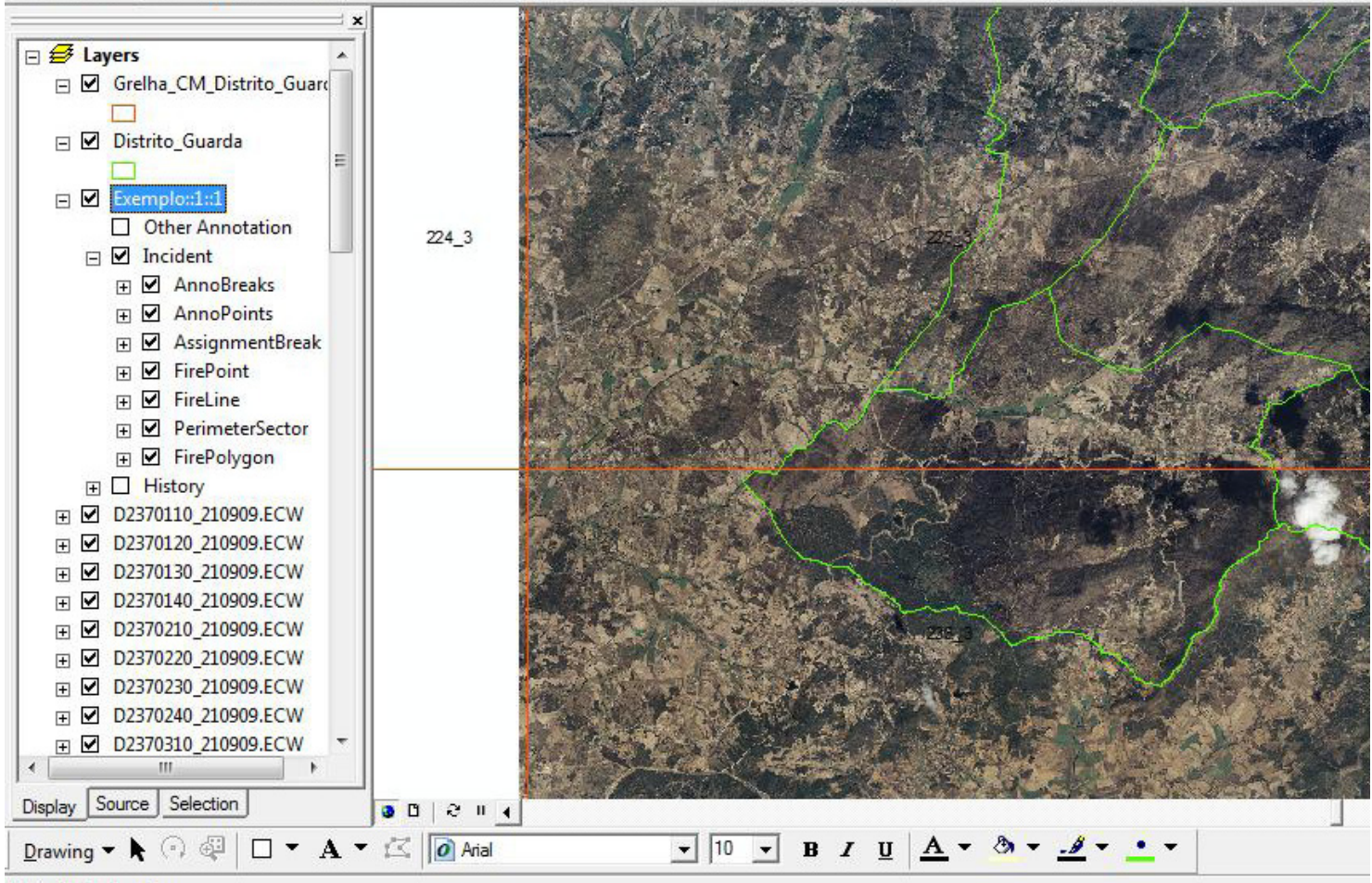

Unda the last action

Fig. 11 - Propriedades da Layer e informação base carregada. 


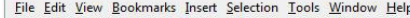

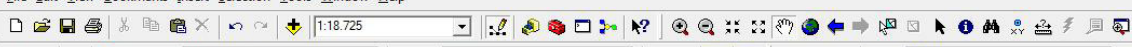

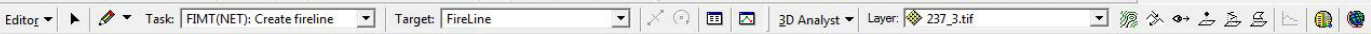
XTools Pro

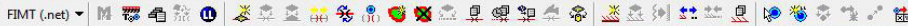

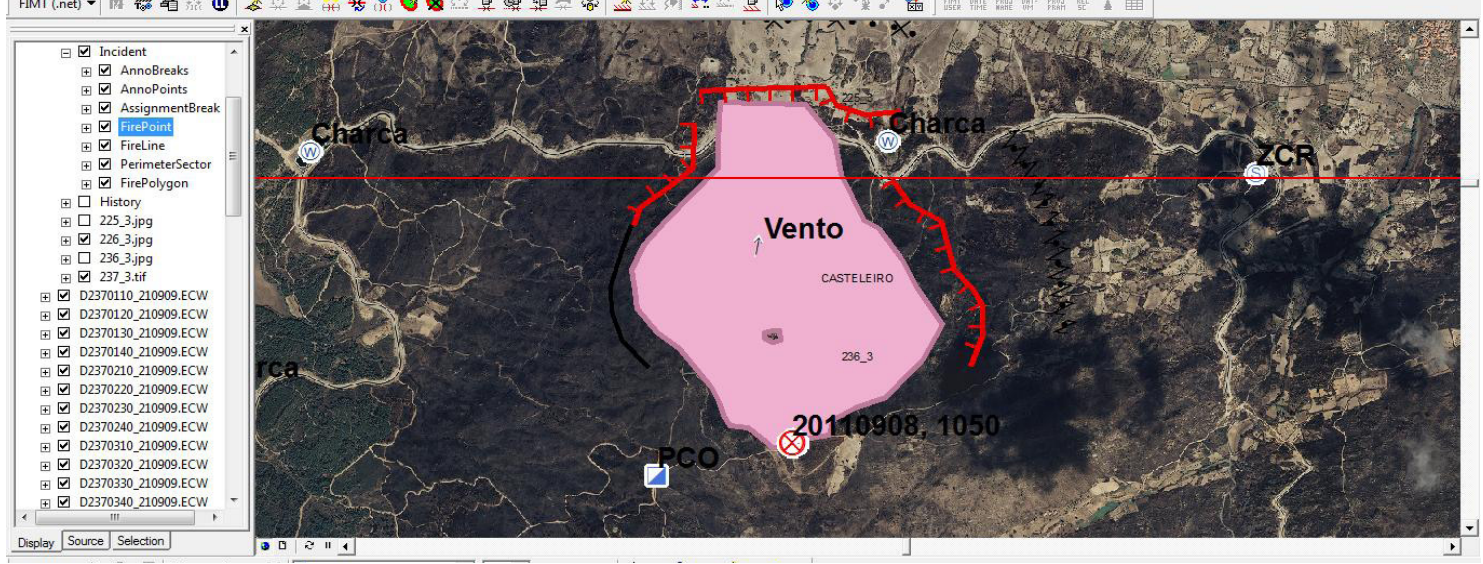

Fig. 14 - Sectorização através de FireLines.

2 Exemplo-mxd - ArcMap - Arclnfo

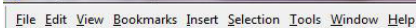

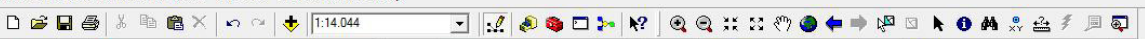

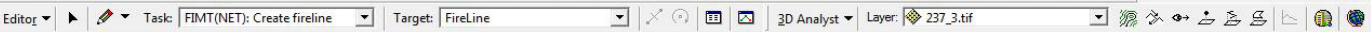

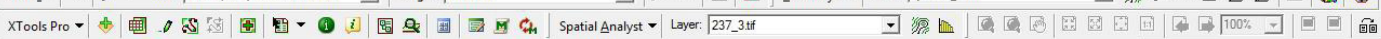

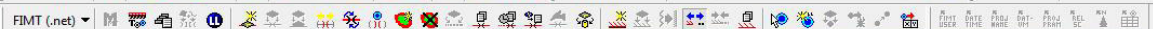

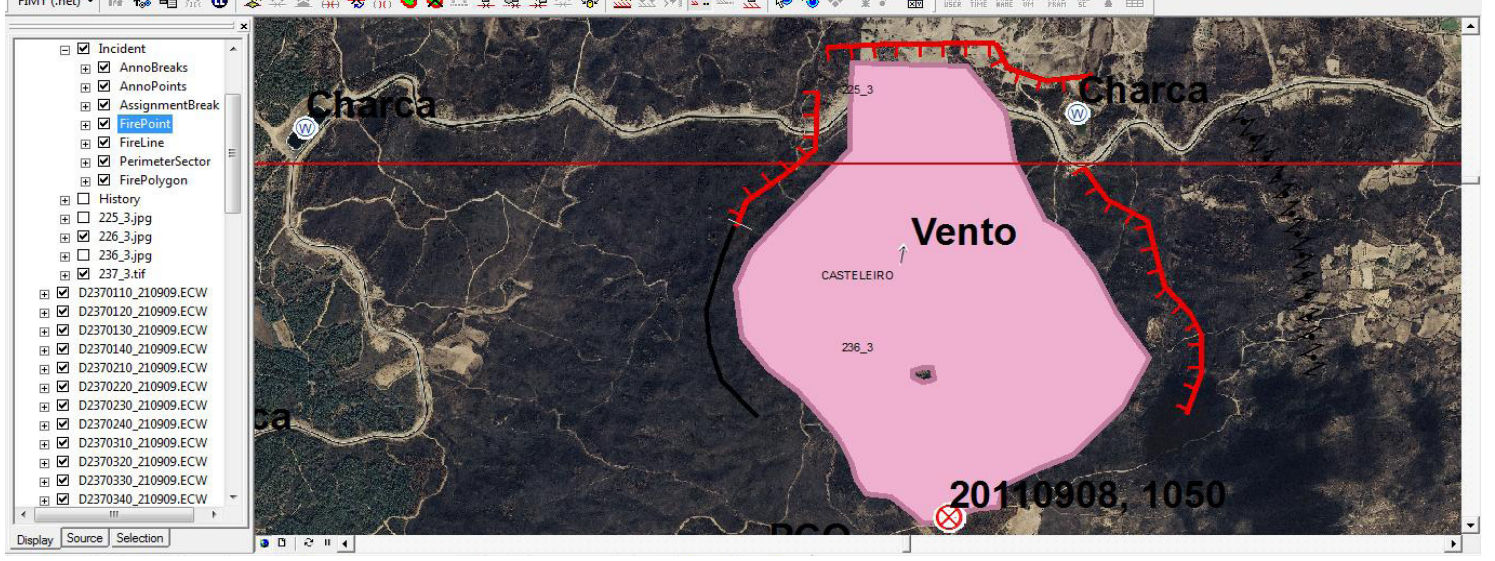

Fig. 15 - Divisão de uma Fireline - Sector Alfa.

Exemplo.mxd -ArcMap - Archno

File Edit View Bookmarks Insert Selection Iools Window Help

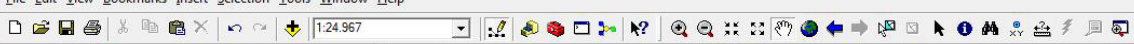

Editon - - Task: FIMT(NET): Create fireline $\sqsupset \mid$ Target: Fireline

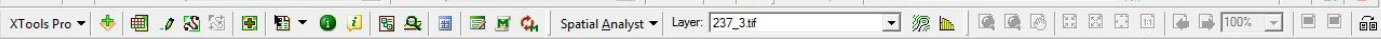

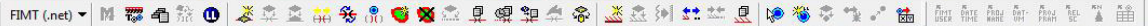

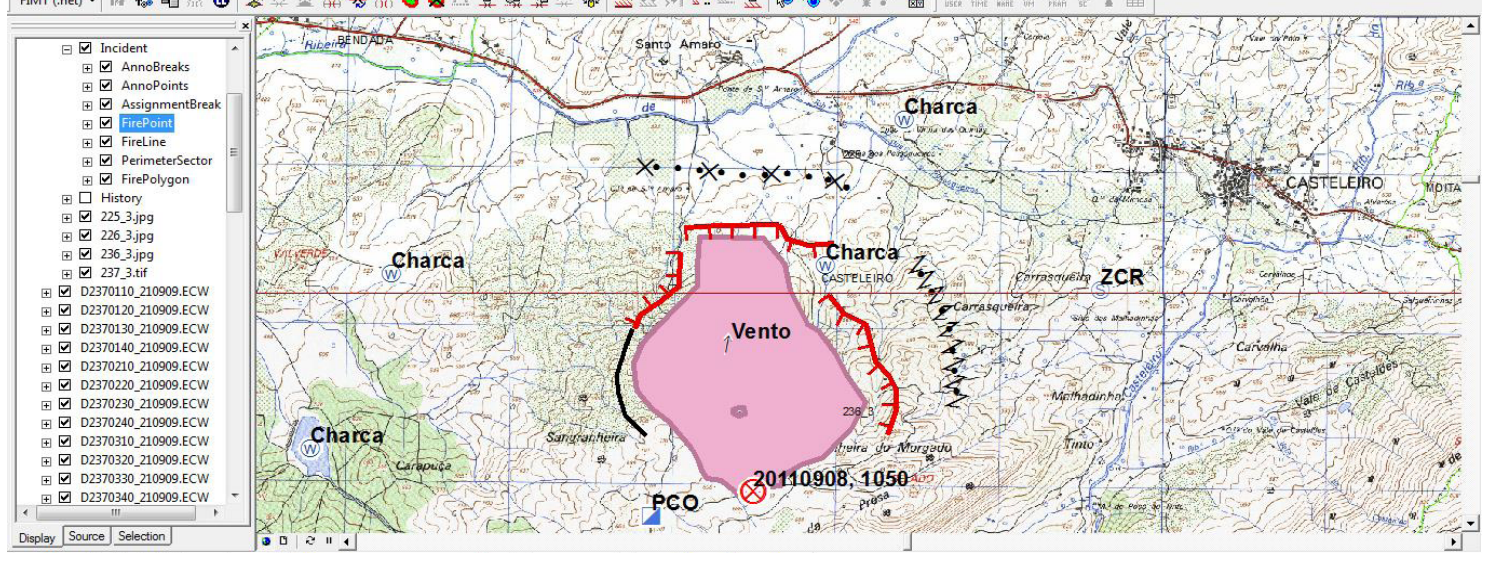

Fig. 16 - Situação táctica (SITAC) com recurso ao FIMT. 


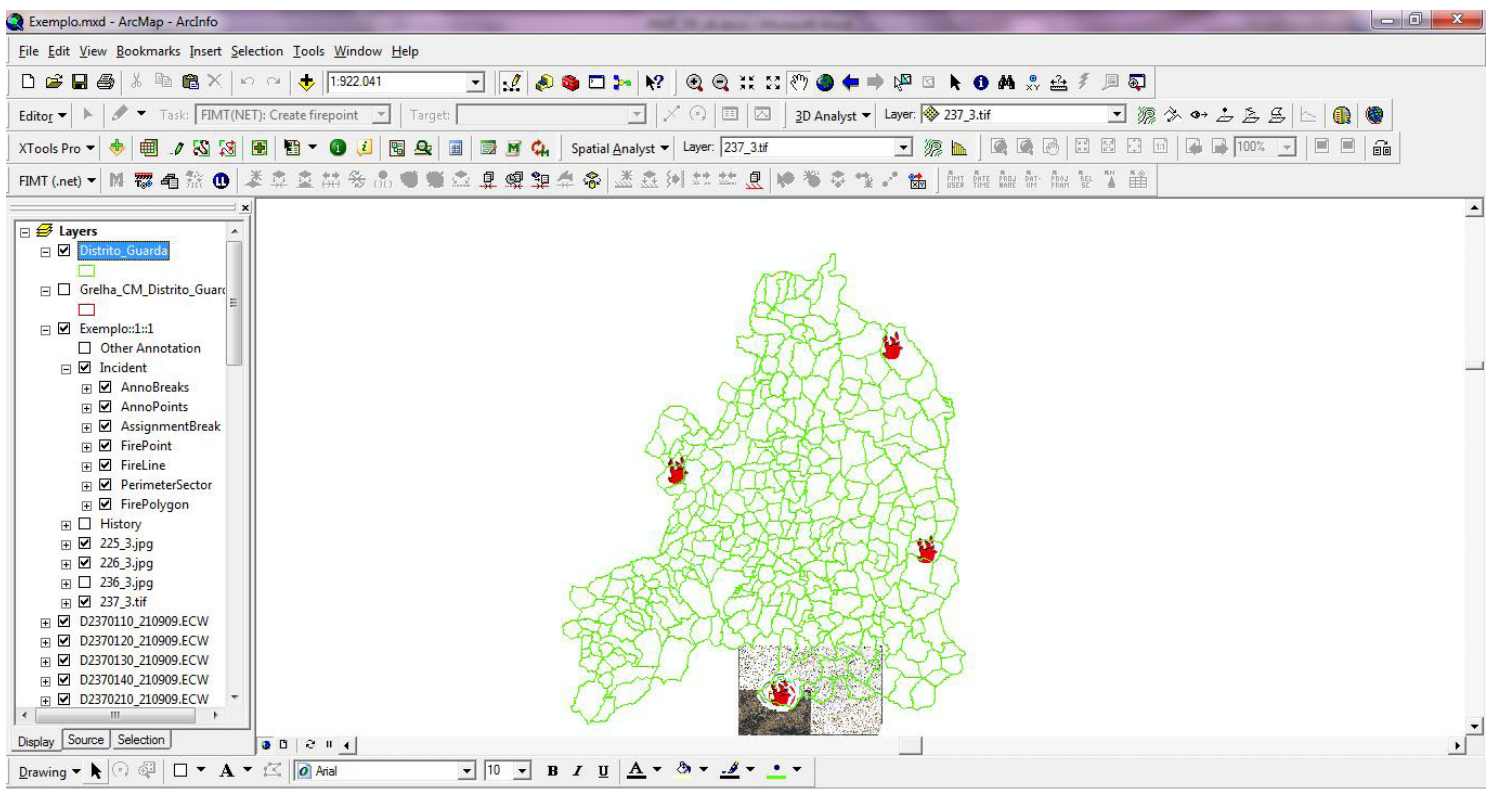

Fig. 17 - Capacidade de marcação de novos focos de incêndio para melhor gestão de meios.

\section{Conclusões}

O FIMT, extensão desenvolvida nos EUA, tem-se apresentado até hoje como uma mais-valia no combate aos incêndios florestais nesse país. Como prova disso, temos os recentes desenvolvimentos sofridos pela extensão, nomeadamente as suas versões para ArcGis 9.3 e, mais recentemente, para o ArcGis 10 .

A aplicação desta tecnologia, embora sempre sujeita à necessidade de sofrer modificações para aplicação em Portugal, eleva o nível de profissionalismo e domínio tecnológico que o planeamento e tomada de decisão exige para um nível completamente diferente do atual.

Assim, o aproveitamento desta extensão para aplicação nos Veículos de Planeamento, Comando e Comunicações que actualmente existem em Portugal seria extremamente útil, permitindo a montagem de um Posto de Comando Avançado e possibilitando assim a tomada de decisão junto à primeira linha de combate.

\section{Referências bibliográficas}

ArcGIS Application for Wildfire Incident Management Version 9.2.0.2, User's Guide Revised: July 2007, USDA Forest Service., USA.

Bombeiros - http://www.bombeiros.pt. Acedido em Julho e Setembro de 2011.

Incêndio Florestal - http://pt.wikipedia.org/wiki/Inc\%C3\%AAndio_ florestal. Acedido em Maio de 2011.

"FIMT - http://www.fs.fed.us/r2/spf/fire_incident/ index2.shtml. Acedido em Maio de 2011.

Fire Incident" - http://gacc.nifc.gov/rmcc/fire_incident/ index.html. Acedido em Junho de 2011.

Fire Incident Mapping Tool - http: / / fire-incident-mappingtool-fimt extensio.software.informer.com/. Acedido em Setembro de 2011. 